\title{
Quantitative texture features as objective metrics of enhancement heterogeneity in hypertrophic cardiomyopathy
}

\author{
Rebecca E Thornhill ${ }^{1,2^{*}}$, Myra Cocker ${ }^{3}$, Girish Dwivedi ${ }^{3}$, Carole Dennie ${ }^{1,2}$, Lyanne Fuller $^{3}$, Alexander Dick ${ }^{3}$, \\ Terrence Ruddy ${ }^{3}$, Elena Pena ${ }^{1,2}$
}

From 17th Annual SCMR Scientific Sessions

New Orleans, LA, USA. 16-19 January 2014

\section{Background}

Hypertrophic cardiomyopathy (HCM) results in myocardial disarray, hypertrophy and fibrosis. Late gadolinium enhanced MRI (LGE) can assess the presence and extent of fibrosis, which is associated with the development of arrhythmias and sudden cardiac death. However, enhancement may not always be present or only sparsely distributed. Thus, one of the challenges is how best to describe heterogeneous LGE patterns in an objective fashion that informs clinical decision making. Quantitative texture features may provide clinicians with an objective means of describing the heterogeneity of LGE patterns in HCM. We hypothesized that hypertrophied segments would exhibit greater grey-level heterogeneity than both (a) non-hypertrophied segments in HCM patients, and (b) healthy volunteers.

\section{Methods}

We prospectively recruited $12 \mathrm{HCM}$ patients and 4 healthy volunteers. Functional (bSSFP cine) and LGE (phase-sensitive inversion recovery spoiled GRE, 10-15 min post injection of $0.2 \mathrm{mmol} / \mathrm{kg}$ Gd-DTPA) images were acquired in short-axis orientation (SAO), as well as in one 4-chamber slice. We measured the maximum thickness on the end-diastolic cine frame in the 17 segments (AHA model). Segments measuring $>15 \mathrm{~mm}$ on SSFP images were considered hypertrophic $(\mathrm{H}+)$. Segments were categorized as fibrotic $(\mathrm{F}+)$ if $>20 \%$ of pixels were enhanced ( $>5 \mathrm{SD}$ nulled myocardium). The extent of myocardial fibrosis on LGE imaging and textural features (run-length non-uniformity, RLNU, and

${ }^{1}$ Medical Imaging, The Ottawa Hospital, Ottawa, Ontario, Canada Full list of author information is available at the end of the article grey-level non-uniformity, GLNU [Galloway 1975]) were assessed for each segment. Differences in RLNU and GLNU among segment groups $(\mathrm{H}+/ \mathrm{F}+, \mathrm{H}+/ \mathrm{F}-, \mathrm{H}-/ \mathrm{F}+$, $\mathrm{H}-/ \mathrm{F}-$, and healthy) were assessed by Kruskal-Wallis tests.

\section{Results}

Of 192 segments we found; $7 \mathrm{H}+/ \mathrm{F}+, 9 \mathrm{H}+/ \mathrm{F}-, 29 \mathrm{H}-/ \mathrm{F}$ + , and $147 \mathrm{H}$-/F-. Median +/-interquartile ranges for RLNU and GLNU for each HCM group, as well as for the 64 segments obtained from healthy volunteers are depicted in Figure 1 ( $\mathrm{P}<0.0001$, for RLNU and GLNU). Post-hoc analysis revealed that RLNU and GLNU were significantly greater in $\mathrm{H}+$ than $\mathrm{H}$ - segments $(\mathrm{P}=0.006$ and $\mathrm{P}=0.0002$, respectively). Both RLNU and GLNU in $\mathrm{H}-/ \mathrm{F}-\mathrm{HCM}$ segments were greater than in healthy volunteers $(\mathrm{P}=0.009$ and $\mathrm{P}<0.0001$, respectively).

\section{Conclusions}

Quantitative textural features related to LGE heterogeneity appear elevated in patients with HCM, even in nonhypertrophic segments. In addition, significant statistical differences were found in the textural features between non-hypertrophic, non-fibrotic segments of HCM patients and healthy volunteers. Thus, RLNU and GLNU show potential for markers of incipient cardiomyopathic changes among HCM patients and may provide helpful tools for differentiating diverse phenotypic expressions of the disease from healthy patients, pending further validation.

\section{Funding}

Nothing to disclose. 

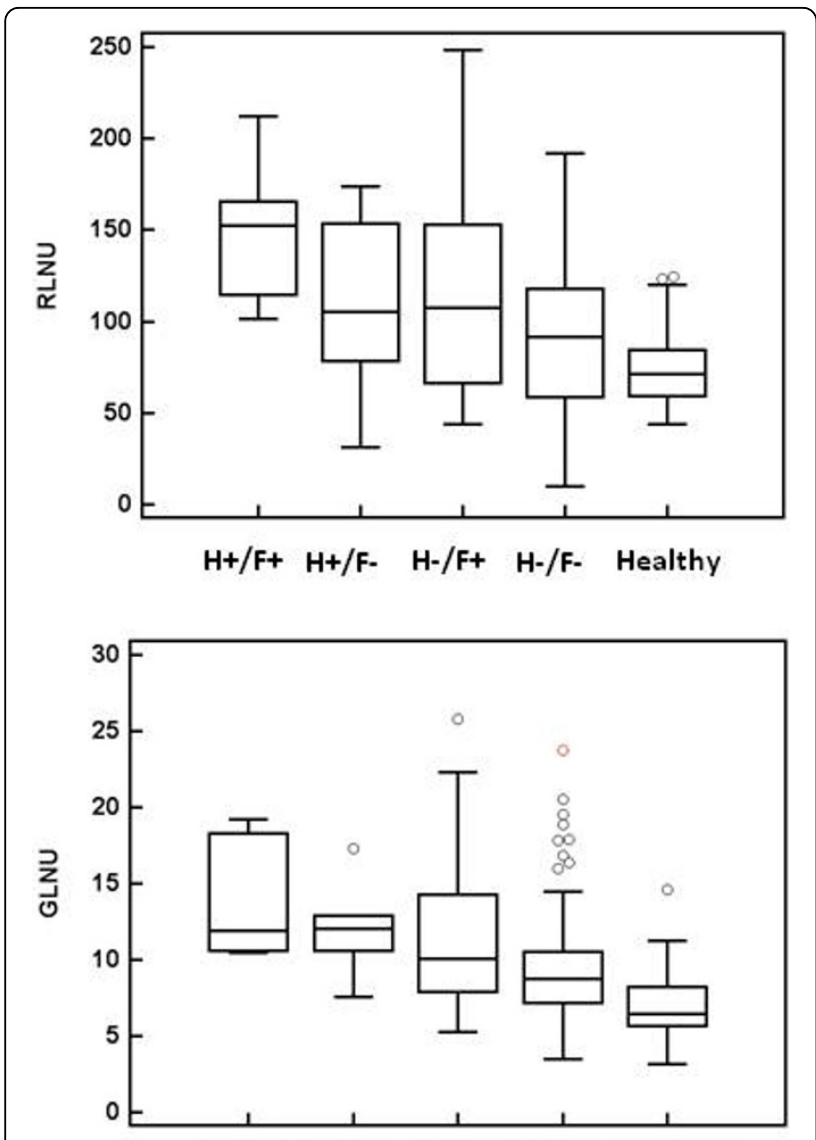

$\mathrm{H}+$ /F+ H+/F- H-/F+ H-/F- Healthy

Figure 1 Box and whisker plots indicating median and interquartile ranges for run-length and grey-level nonuniformity features: Hypertrophic/Fibrotic $(\mathrm{H}+/ \mathrm{F}+)$, Hypertrophic/ Non-Fibrotic (H+/F-), Non-hypertrophic/Fibrotic $(\mathrm{H}-/ \mathrm{F}+)$, Nonhypertrophic/Non-Fibrotic (H-/F-), and Healthy segments.

\section{Authors' details}

'Medical Imaging, The Ottawa Hospital, Ottawa, Ontario, Canada. ${ }^{2}$ Radiology, University of Ottawa, Ottawa, Ontario, Canada. ${ }^{3}$ Cardiology, University of

Ottawa Heart Institute, Ottawa, Ontario, Canada.

Published: 16 January 2014

doi:10.1186/1532-429X-16-S1-P351

Cite this article as: Thornhill et al:: Quantitative texture features as objective metrics of enhancement heterogeneity in hypertrophic

cardiomyopathy. Journal of Cardiovascular Magnetic Resonance 201416 (Suppl 1):P351.

\section{Submit your next manuscript to BioMed Central and take full advantage of:}

- Convenient online submission

- Thorough peer review

- No space constraints or color figure charges

- Immediate publication on acceptance

- Inclusion in PubMed, CAS, Scopus and Google Scholar

- Research which is freely available for redistribution

Submit your manuscript at www.biomedcentral.com/submit 